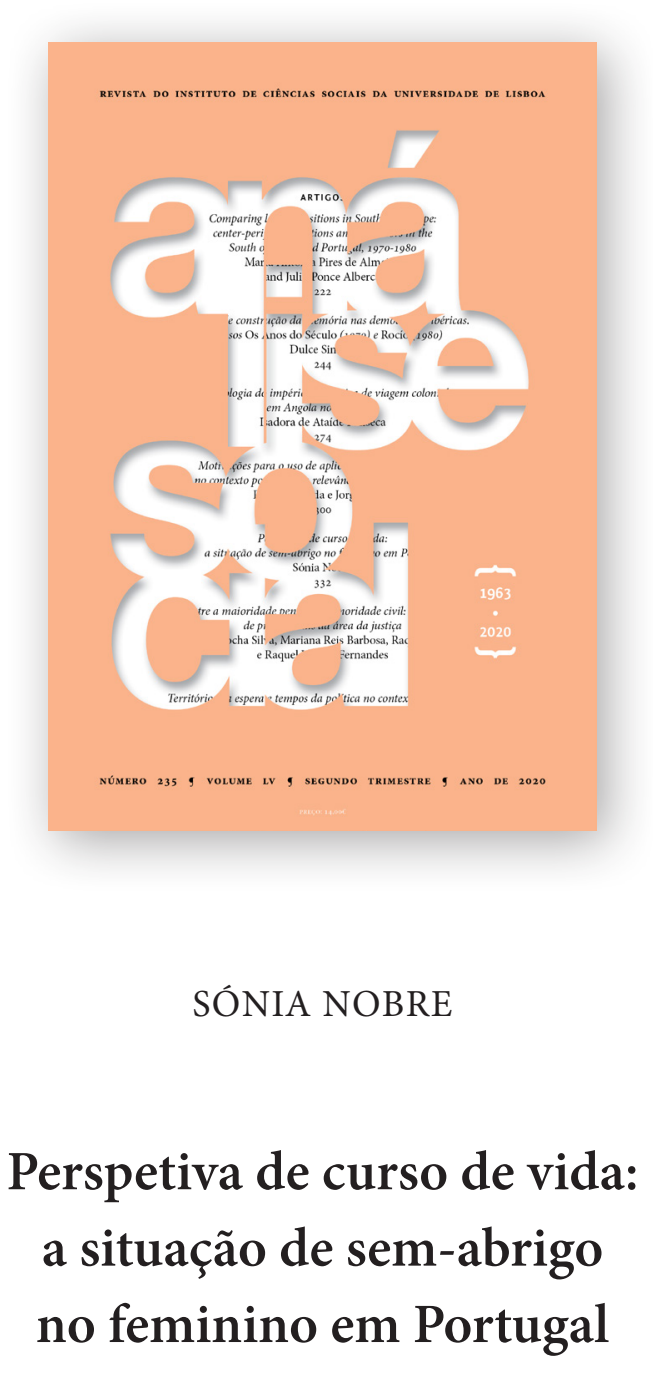

\title{
Perspetiva de curso de vida: a situação de sem-abrigo no feminino em Portugal
}

Análise Social, LV (2. $\left.{ }^{\circ}\right), 2020$ (n. $\left.{ }^{\circ} 235\right)$, pp. 332-354 https://doi.org/10.31447/ASO0032573.2020235.05

ISSN ONLINE 2182-2999 
Análise Social, 235, LV (2. $\left.{ }^{\circ}\right), 2020,332-354$

Perspetiva de curso de vida: a situação de sem-abrigo no feminino em Por tugal. Este artigo aborda as limitações no conhecimento existente sobre a situação de sem-abrigo, especialmente sobre as mulheres em situação de sem-abrigo em Portugal. Defende-se que a perspetiva de curso de vida é uma ferramenta útil para guiar análises compreensivas sobre este fenómeno, designadamente sobre os seus mecanismos causais. Esta ideia fundamenta-se numa revisão de literatura e consolida-se com a apresentação e discussão de duas histórias de vida de mulheres em situação de sem-abrigo inseridas num projeto de investigação em curso. Finalmente, debatemse as implicações práticas relativas à aplicação da perspetiva de curso de vida ao estudo da situação de sem-abrigo.

PALAVRAS-CHAVE: Situação de sem-abrigo; mulheres em situação de sem-abrigo; perspetiva de curso de vida; investigação biográfica.

Life course perspective and female homelessness in Portugal. This article addresses the current limitations on the knowledge about homelessness, particularly about women experiencing homelessness in the Portuguese context. It is argued that the life course perspective is a useful tool to guide comprehensive analyses of homelessness, namely those that focus on its causal mechanisms. This argument is based on a literature review about this topic and reinforced through the presentation and discussion of two life histories of women experiencing homelessness which derive from an ongoing research project. The practical implications of applying a life course perspective to the study of homelessness are discussed later on.

KEYWORDS: Homelessness; women experiencing homelessness; life course perspective; biographical research.

https://doi.org/10.31447/Asoo032573.2020235.05 


\section{Perspetiva de curso de vida: a situação de sem-abrigo no feminino em Portugal}

\section{INTRODUÇÃO ${ }^{1}$}

O modo de definir a situação de sem-abrigo (ssa) não é consensual, mas qualquer definição deve ser objeto de reflexão porquanto condiciona a quantificação e a compreensão do fenómeno em geral e da situação das mulheres em particular (Löfstrand e Quilgars, 2016). A ssa tem designado os indivíduos que estão literalmente sem teto, e aqueles que pernoitam em centros de alojamento temporário (Pleace, 2016a). Estas são as manifestações de sem-abrigo tendencialmente contabilizadas e, portanto, aquelas a que se tem conferido maior visibilidade. Estas são também as tipologias em que os homens predominam, o que tem concorrido para se criar e perpetuar a noção de que a SSA é um fenómeno quase exclusivamente masculino (Pleace, 2016b). Contudo, esta é uma visão redutora uma vez que os indivíduos sem domicílio próprio, em especial as mulheres, tendem a recorrer a um leque mais vasto de soluções para pernoitar ou residir, por exemplo coabitando temporariamente com familiares e amigos (Edgar e Doherty, 2001; Pleace, 2016b).

A Tipologia Europeia de Situação de Sem-Abrigo e Exclusão Habitacional ${ }^{2}$ é uma ferramenta conceptual e operacional que define a ssa de uma forma mais ampla, abrangendo um conjunto de situações habitacionais diversificado (Busch-Geertsema, 2010). A sua utilização permite abranger um número mais elevado de pessoas em ssA e incluir situações habitacionais onde é mais provável encontrar mulheres sem domicílio próprio do que nas ruas ou em

1 Investigação feita no âmbito da bolsa de doutoramento com a referência SFRH/BD/104321/ /2014, atribuída pela Fundação para a Ciência e a Tecnologia.

2 Esta tipologia foi concebida pelo Observatório Europeu sobre a Situação de Sem-Abrigo e tem sido empregue em vários países Europeus (Busch-Geertsema, 2010; Edgar, 2012). 
centros de alojamento temporário. Assim, esta tipologia pode contribuir para determinar com maior acuidade a extensão da ssa no feminino e, por conseguinte, torná-la mais visível (Baptista, 2010; Pleace, 2016b). Atualmente não é possível quantificar as mulheres (e os homens) em ssA na Europa por falta de dados consistentes e comparáveis. Estima-se que as mulheres representem entre $12 \%$ (Espanha) e 38\% (França) do total da população em ssA, sendo que em Espanha se contabilizaram 22932 pessoas em SsA em 2012, ao passo que em França foram quantificadas 142000 pessoas em ssA em 2011 (Busch-Geertsema et al., 2014). Estas proporções podem aumentar consideravelmente se se empregarem definições mais abrangentes, o que significa que a ssA no feminino é um problema relevante na Europa (Löfstrand e Quilgars, 2016).

A investigação sobre a ssa conduzida ao nível internacional, e especificamente na Europa, carece de uma perspetiva de género (Edgar e Doherty, 2001; Mayock e Bretherton, 2016). O conhecimento existente sobre as mulheres em ssa é limitado, embora a necessidade de olhar para a ssA com uma perspetiva de género seja reiterada por investigadores e no plano político (Edgar e Doherty, 2001; Baptista, 2010; Mayock e Bretherton, 2016; Parlamento Europeu, 2016). O género está intimamente ligado a algumas dimensões da ssA, incluindo os mecanismos causais, as experiências vividas em ssA, a relação entre maternidade e ssA, e a utilização dos serviços de apoio. A título exemplificativo, a evidência existente sugere que a desvantagem socioeconómica e a violência de género desempenham um papel de relevo na ssa no feminino, que o recurso a redes de apoio informais é uma reação frequente por parte de mulheres que estão na iminência de ficar em ssA, e que as necessidades destas mulheres diferem das dos homens em vários aspetos, incluindo, por exemplo, as que se relacionam com contraceção, gravidez e existência de crianças dependentes (Edgar e Doherty, 2001; Mayock e Bretherton, 2016). $A$ adoção de uma perspetiva de género que evidencie e ajude a compreender as especificidades das mulheres que se defrontam com uma SSA pode contribuir para uma intervenção mais adequada junto destas pessoas (Mayock, Parker e Sheridan, 2015).

Este artigo propõe-se contribuir para o debate sobre a ssa no feminino, argumentando que a perspetiva de curso de vida pode ser uma orientação teórica útil para aprofundar o conhecimento existente sobre este fenómeno, e especificamente sobre os seus mecanismos causais. $\mathrm{O}$ artigo começa com uma reflexão sobre as abordagens teóricas dominantes no estudo da ssa e sobre as limitações no conhecimento existente sobre este tema. Em seguida introduz-se a perspetiva de curso de vida e explicam-se as suas bases conceptuais. Depois faz-se uma revisão de literatura, visando os estudos que abordaram a ssA sob este prisma teórico e assinalando de que modos contribuíram para 
aprofundar o conhecimento sobre este fenómeno. Segue-se um breve retrato da ssa no feminino em Portugal e um contributo empírico sobre mulheres em ssa com apresentação e discussão de dois estudos de caso. Por fim, discutem-se as implicações práticas e as limitações da perspetiva de curso de vida aplicada à análise da ssa.

\section{O DEBATE TEÓRICO SOBRE A SSA E AS SUAS LIMITAÇÕES}

O debate académico sobre a SSA foi tradicionalmente polarizado, concentrando-se em duas abordagens teóricas distintas que remetiam para explicações individuais versus estruturais deste fenómeno (Neale, 1997; Pleace, 2000). As explicações individuais focavam-se nas características, nos comportamentos e nas problemáticas dos indivíduos em ssa, incluindo adversidades na infância, baixa escolaridade, desvantagem na inserção no mercado laboral, doenças físicas ou mentais limitativas ou incapacitantes e dependência de substâncias psicoativas. Admitia-se que estes fatores vulnerabilizassem os indivíduos, nomeadamente por poderem coartar-lhes o acesso a recursos materiais e financeiros (Neale, 1997; Fitzpatrick, 2005; Pleace, 2016a), e fossem suficientes para explicar a sua ssa (Snow, Anderson e Koegel, 1994). A perspetiva estrutural defendia que a ssa era causada por fatores sistémicos, incluindo os elementos políticos e culturais que alimentam diversas formas de desigualdade, as condições adversas nos mercados laboral e de habitação e o modo de funcionamento do sistema de proteção social, entre outros (Neale, 1997; Fitzpatrick, 2005; Pleace, 2016a).

Entretanto, estas abordagens foram criticadas por serem excessivamente simplistas, entendendo-se que a ssa é demasiado complexa para que possa ser explicada, de forma redutora, através da dicotomia individual-estrutural (Neale, 1997). Nos anos 90 do século xx já se reconhecia, no seio da academia, que estas abordagens eram insatisfatórias para esclarecer este fenómeno. Isto conduziu à necessidade de repensar a ssA, que passou a ser interpretada como o resultado da interação entre fatores individuais e estruturais, o que foi designado como nova ortodoxia ${ }^{3}$ (Pleace, 2000). Segundo a nova ortodoxia, existem fatores individuais predispondo alguns indivíduos para uma maior vulnerabilidade a fatores estruturais que, por sua vez, desencadeiam as condições a partir das quais a ssa se desenvolve. Por outras palavras, a nova ortodoxia estabelece que a ssa advém de uma combinação desfavorável de fatores individuais e estruturais (Fitzpatrick, 2005; Pleace, 2016a).

3 A nova ortodoxia foi desenvolvida nos Estados Unidos da América há mais de duas décadas (Pleace, 2016a). 
Todavia, a nova ortodoxia também foi sujeita a críticas. Desde logo, considera-se que os fatores individuais e estruturais não têm sido especificados com clareza (Somerville, 2013). Em segundo lugar, a nova ortodoxia não elucida como é que a interação entre os fatores individuais e estruturais se processa, nem como é que conduz efetivamente a uma ssa (Fitzpatrick, 2005; Somerville, 2013; Pleace, 2016a). Além disso, não consegue justificar porque é que, de entre indivíduos que partilham fatores individuais e estruturais semelhantes, alguns passam por uma ssA e outros não (Ciapessoni, 2016). Por fim, a nova ortodoxia não reconhece a capacidade de ação das pessoas em ssA. Dito de outro modo, não tem em consideração que as pessoas em ssa são agentes cujas decisões e atuações podem influenciar e moldar as suas trajetórias. Em grande medida, a nova ortodoxia posiciona os indivíduos em ssa como vítimas passivas e impotentes perante as suas vulnerabilidades ou os fatores estruturais que se abatem sobre as suas vidas (Pleace, 2016a).

Alguns autores que têm refletido de um modo crítico sobre a ssa entendem que é imprescindível reequacionar as suas causas e tentar explicar como é que os fatores causais foram interpretados e vivenciados pelas pessoas em SSA, como é que surgiram nas suas vidas e como é que conduziram a uma ssa (Ravenhill, 2008; Somerville, 2013; Pleace, 2016a). Um entendimento mais aprofundado sobre a ssa pressupõe que ela seja enquadrada nas biografias individuais e nos contextos estruturais em que se desenvolve (Snow, Anderson e Koegel, 1994; Somerville, 2013; Pleace, 2016a). Tendo em consideração o diferencial de género na investigação sobre a ssA a que se aludiu anteriormente, estas lacunas estendem-se naturalmente à ssa no feminino.

Por outro lado, têm vindo a ser reconhecidas a complexidade da SSA, a interação de uma multiplicidade de fatores nela implicados, e a heterogeneidade da população em ssa (Neale, 1997; Lee, Tyler e Wright, 2010; Nooe e Patterson, 2010). Finalmente, a ssa vem sendo percecionada como um processo que se desenrola nas vidas de alguns indivíduos e não como uma condição estática (Ravenhill, 2008; Lee, Tyler e Wright, 2010).

Assim, parece ser fundamental adotar uma visão abrangente no estudo deste fenómeno que seja capaz de analisar as vidas das pessoas em ssa e de o fazer abarcando a sua multidimensionalidade e a sua temporalidade. É neste sentido, e com este intuito, que a perspetiva de curso de vida pode constituir uma mais-valia para a compreensão da ssa. 


\section{A PERSPETIVA DE CURSO DE VIDA E OS SEUS PRESSUPOSTOS TEÓRICOS}

A perspetiva de curso de vida conta com mais de cinco décadas e tem sido empregue em várias disciplinas científicas e aplicada a diversos campos de pesquisa. O sociólogo Americano Glen Elder Jr. e os seus colegas estão entre os autores que a idealizaram e que contribuíram para o seu desenvolvimento (Elder, Johnson e Crosnoe, 2003; Hutchison, 2011). Pode ser entendida como uma ferramenta teórica que permite nortear o estudo das vidas humanas nos seus contextos (Elder, Johnson e Crosnoe, 2003). Para a sua compreensão é necessário mencionar e explanar alguns conceitos-chave: trajetórias, transições, acontecimentos de vida e pontos de viragem.

As trajetórias representam padrões prolongados de estabilidade e mudança nas vidas dos indivíduos. As vidas humanas podem ser conceptualizadas como uma série de trajetórias que se intersetam, tais como trajetórias familiar, educacional, laboral, habitacional e de saúde. Estas trajetórias não são concebidas como percursos lineares que seguem um rumo previsível em consonância com uma lógica determinista. Pelo contrário, as trajetórias englobam descontinuidades, ruturas mais ou menos abruptas e reviravoltas (Elder, Johnson e Crosnoe, 2003; Hutchison, 2011).

As transições referem-se a modificações no estatuto ou no papel dos indivíduos. As transições estão incorporadas nas trajetórias e, nesse sentido, as trajetórias são parcialmente constituídas por transições. São exemplos de transições a saída da casa parental, a obtenção de emprego ou a reforma. Quanto aos acontecimentos de vida, trata-se de ocorrências significativas que envolvem mudanças relativamente repentinas e com efeitos relevantes a longo prazo, tanto positivos como negativos. Os acontecimentos de vida remetem para os eventos em si e não para as transições decorrentes desses eventos. Exemplificando, o casamento é um acontecimento de vida que precipita uma transição (casar) conducente a uma trajetória marital que se prevê ou supõe que seja prolongada, confira algum grau de estabilidade e possa envolver outras transições no seu decurso (Elder, Johnson e Crosnoe, 2003; Hutchison, 2011).

Por último, os pontos de viragem sinalizam mudanças substanciais e duradouras nas trajetórias individuais, podendo ser benéficas ou deletérias (Elder, Johnson e Crosnoe, 2003; Hutchison, 2011). As transições podem transformar-se em pontos de viragem se envolverem conflitos familiares, sucederem em fases atípicas da vida ou tiverem consequências prejudiciais que não tenham sido antecipadas pelo indivíduo. Os acontecimentos de vida podem constituir-se como pontos de viragem se tiverem impacto nas oportunidades ao alcance do indivíduo ou gerarem uma alteração persistente no seu ambiente 
envolvente. Os indivíduos atribuem significados aos acontecimentos de vida e, portanto, eles serão tidos como pontos de viragem em função das apreciações pessoais e subjetivas acerca da sua existência e da sua relevância (Hutchison, 2011).

A perspetiva de curso de vida é caracterizada por cinco princípios basilares: desenvolvimento ao longo da vida; tempo histórico, social e pessoal; posicionamento geográfico e social; vidas interligadas; e ação humana (Elder, Johnson e Crosnoe, 2003; Hendricks, 2012).

O princípio do desenvolvimento ao longo da vida significa que o desenvolvimento humano é entendido como um processo que ocorre desde o nascimento até à morte. Este processo é composto pelas dimensões biológica, psicológica e social e pode materializar-se em ganhos e na obtenção de recursos, mas também em perdas (Elder, Johnson e Crosnoe, 2003; McDonald, 2011).

Outro elemento essencial para a compreensão desta perspetiva é a dimensão temporal e a sua interseção com as trajetórias individuais. Esta temporalidade pode ser decomposta em três vertentes distintas, mas inter-relacionadas: tempo histórico, tempo social e tempo pessoal. Considera-se que o curso de vida deve ser analisado à luz do período histórico no qual se insere e que, por sua vez, o afeta e influencia. O tempo social refere-se aos marcos estipulados pelas convenções, normas e expectativas vigentes em cada sociedade, como a frequência escolar, a participação no mercado de trabalho ou a reforma. Ou seja, o tempo social condiciona as vidas dos indivíduos na medida em que estrutura, de um modo mais ou menos flexível, os seus passos e os seus ritmos (Hutchison, 2011; Hendricks, 2012). Por fim, a perspetiva de curso de vida interpela o tempo pessoal, ao admitir que o impacto de um mesmo tipo de acontecimentos e experiências possa ser sentido e interpretado de modo díspar pelos indivíduos, consoante as fases da vida em que se encontrem (Elder, Johnson e Crosnoe, 2003; Hendricks, 2012). A título de exemplo, o falecimento de uma figura parental na infância é um acontecimento que surge numa fase atípica da vida e este mesmo evento poderá ser vivido de outra forma quando ocorre na idade adulta (Kennedy et al., 2010).

De acordo com a perspetiva de curso de vida, o posicionamento dos indivíduos pode ser equacionado sob dois prismas distintos, mas interligados: geográfico e social. Por um lado, os cursos de vida devem ser examinados tendo em atenção a influência exercida pelos lugares geográficos onde se inscrevem e de onde emergem (Elder, Johnson e Crosnoe, 2003; Hendricks, 2012). Por outro lado, o posicionamento social dos indivíduos, que é tido como o equivalente à sua condição socioeconómica, influencia as suas práticas quotidianas e os modos como as suas vidas são experienciadas e se desdobram. 
O posicionamento social determina uma maior ou menor gama de recursos e de oportunidades disponíveis e constrange a atuação individual em graus variáveis. À luz desta perspetiva, tanto as oportunidades como os constrangimentos são passíveis de afetar e de ser afetados pelos cursos de vida (Hendricks, 2012).

Esta perspetiva teórica enfatiza a interdependência das vidas humanas e os modos como os indivíduos estão inevitavelmente ligados (Elder, Johnson e Crosnoe, 2003; Hutchison, 2011). O princípio das vidas interligadas sublinha a importância das interações sociais, porquanto operam como recursos ou como dificuldades e contribuem para moldar os cursos de vida (McDonald, 2011; Hendricks, 2012). As interações sociais indicam as relações estabelecidas entre o indivíduo e os membros da família, os amigos da escola, os colegas de trabalho e quaisquer outros grupos com os quais tenha contacto ou afinidades (Hendricks, 2012). Contudo, segundo esta orientação teórica, a família detém um papel de relevo, pois funciona como o contexto primário do desenvolvimento humano, como uma fonte de capital social em termos de modelos e fornecimento de redes de suporte, e como um possível manancial de apoio, nomeadamente a nível material (Hutchison, 2011).

Por último, o princípio da ação humana define que o curso de vida é igualmente influenciado e moldado pelo desempenho ativo do indivíduo. Segundo esta perspetiva teórica, a ação humana designa as decisões e as atuações dos indivíduos que são suscetíveis de modificar os seus cursos de vida. Elas são tomadas tendo em conta a perceção dos indivíduos acerca das alternativas existentes e as oportunidades e constrangimentos relacionados com as circunstâncias históricas, culturais e sociais em que se inserem (Elder, Johnson e Crosnoe, 2003; Hutchison, 2011).

\section{DA PERSPETIVA TEÓRICA AO ESTUDO DA SSA}

$\mathrm{Na}$ literatura internacional encontram-se trabalhos que, ao adotar a perspetiva de curso de vida, contribuíram para o conhecimento sobre a ssA, em especial desvendando e/ou aprofundando certos mecanismos causais.

Ravenhill (2008) fornece uma visão detalhada e compreensiva sobre as causas da SSA, explicando os mecanismos através dos quais certos fatores, como o abandono escolar precoce, ou o abuso na infância, podem ter efeitos a longo prazo e propiciar uma ssa. Este estudo sugere que a ssa é um processo resultante de uma combinação de fatores adversos que sucedem ao longo do tempo com consequências perduráveis e impactos diversificados, que se articulam de formas complexas. Mas mais do que a ocorrência dos fatores per se, o que conduz à ssa é o seu efeito cumulativo e o modo como os 
próprios indivíduos e os que os rodeiam os interpretam e reagem perante eles. A esta equação acrescenta-se a influência protetora de fatores como a existência de redes sociais fortes e benignas, ou um elevado nível de escolaridade, que podem amortecer ou contrabalançar fatores nefastos. Tendo constatado que estes fatores surgem amiúde em fases precoces das vidas das pessoas em ssA, a autora defende que é fundamental analisar as trajetórias individuais desde a infância, por forma a compreender melhor como é que elas se vão traçando e encaminhando para a ssA.

Esta ideia é corroborada por Kennedy et al. (2010), a partir de uma análise dos fatores de risco que conduziram jovens mães a uma ssa. Estes autores identificaram cadeias de riscos que se acumularam nas suas infâncias e adolescências, incluindo a ausência de suporte por parte dos cuidadores (tipicamente por falecimento, abandono ou rejeição), a exposição a múltiplas formas de violência, a pobreza, o abandono escolar precoce e o envolvimento com os sistemas de proteção de menores. Este efeito cumulativo e a escassez de redes de suporte confluíram num isolamento progressivo e no esgotamento de opções que lhes permitissem evitar a ssa. Contudo, alguns dos impactos destas cadeias de risco foram minimizados pela intervenção dos serviços de apoio. O suporte material e o estabelecimento de relações positivas com alguns profissionais trouxeram a estas jovens recursos e oportunidades, para além de uma influência salutar em termos de autoconfiança e otimismo quanto ao futuro. Assim, estas interações constituíram pontos de viragem que alavancaram o redirecionar das suas trajetórias.

Tyler e Schmitz (2013) também enfatizam a necessidade de analisar as trajetórias das pessoas em ssa desde a infância, baseando-se num estudo que se debruça sobre as histórias familiares de jovens adultos em ssA. Estas histórias familiares permitem compreender os contextos sociais de origem destes indivíduos, os motivos que os levaram a sair das casas parentais precocemente e as transições vivenciadas desde então, que se materializaram em trajetórias rumo à SSA.

Outro estudo relevante é o de McDonald (2011), que abordou os despejos conducentes à ssa como processos que se desenvolvem ao longo do tempo e que estão invariavelmente ligados a várias dimensões da vida humana e às políticas que regem este sector. Ciapessoni (2016), por sua vez, considera que a principal contribuição teórica da perspetiva de curso de vida é a possibilidade de evidenciar a natureza relacional e interdependente das esferas da vida humana que estão implicadas na ssa e, por conseguinte, mostrar como é que certos acontecimentos ou transições numa dessas esferas têm impacto nas outras. Por fim, alguma investigação sobre a SsA nas fases tardias da vida tem sugerido que se trata de um culminar de acontecimentos adversos em diversas 
áreas (por exemplo educação, emprego, saúde, família, fontes de rendimento), que ocorrem ao longo da vida, que estão inter-relacionados e que compõem trajetórias de precariedade passíveis de desembocar em ssa ${ }^{4}$ (Grenier, Barken e McGrath, 2016a; Lacey et al., 2016).

Em suma, a investigação guiada por uma perspetiva de curso de vida tem fornecido dados que podem traduzir-se num conhecimento mais compreensivo sobre a SsA e contribuir para colmatar algumas das deficiências apontadas à nova ortodoxia. Em particular, tem retratado a ssa como um processo que se desenrola ao longo do tempo e que beneficia de análises que sejam capazes de abranger a multiplicidade de esferas que compõem e definem as trajetórias humanas, os contextos estruturais que as envolvem e influenciam, e o papel ativo dos indivíduos no delineamento das suas vidas.

\section{AS MULHERES EM SSA EM PORTUGAL}

Os números oficiais sobre a ssa em Portugal são dispersos e insuficientes, tornando-se assim difícil contabilizar as mulheres em ssa. De entre os dados mais recentes salienta-se que, em 2013, a Segurança Social registou 4420 processos de ssA, 24\% dos quais relativos a mulheres (ISS, 2017). Um inquérito conduzido em Portugal continental entre fevereiro e maio de 2018 contabilizou 3396 pessoas em ssa segundo a definição nacional, que se limita às pessoas sem teto e às que residem em alojamentos temporários ou em quartos pagos pelos serviços sociais. Foram ainda contabilizadas 11113 pessoas em risco habitacional (ex: coabitando temporariamente com familiares/amigos por falta de domicílio próprio), que seriam consideradas ssa ou exclusão habitacional à luz da Tipologia Europeia mencionada na introdução deste artigo ${ }^{5}$ (GIMAE, 2018).

Em Portugal, a investigação dedicada a mulheres em ssa é escassa. Os estudos existentes focam-se em mulheres sem teto, utilizadoras dos serviços de apoio e/ou residentes em centros de alojamento temporário. Alguns destes trabalhos são maioritariamente descritivos e, no que concerne às causas de sem-abrigo no feminino, estas tendem a ser nomeadas e não enquadradas nas biografias das mulheres estudadas (Costa e Baptista, 1999; Gomes, 2002; Martins, 2017). Os estudos que fornecem uma visão mais compreensiva sobre as mulheres em ssa explicam de forma mais detalhada e abrangente como

4 O limite de idade para definir ssa em fases tardias da vida tem sido 50 anos, o que se deve ao envelhecimento prematuro das pessoas em ssa e a taxas mais elevadas de mortalidade precoce entre os indivíduos sem teto do que na população em geral (Grenier et al., 2016b).

5 Neste inquérito, os números de pessoas em ssa e em situação de risco habitacional não foram desagregados por sexo. 
é que a ssa se desenvolveu nas suas vidas. No entanto, as trajetórias de vida destas mulheres raramente são exploradas em profundidade desde a infância e estas análises baseiam-se em amostras muito reduzidas (Barros, 2010; Machado, 2012; Lopes, 2017). Por conseguinte, o conhecimento sobre as vidas e as experiências das mulheres em ssa é muito limitado.

Está em curso um projeto de investigação, de natureza exploratória, que se propõe aprofundar o conhecimento existente sobre a ssA no feminino em Portugal. Este estudo diferencia-se dos demais até à data publicados em vários aspetos dos quais se salientam dois. Primeiro, é adotada uma definição ampla de sem-abrigo - a Tipologia Europeia - porque permite incluir mulheres sem domicílio próprio que têm estado à margem das definições convencionais e, frequentemente, dos serviços de apoio. Poder-se-á, assim, abarcar uma maior diversidade de situações e tornar mais visíveis algumas trajetórias, vivências e necessidades de mulheres sem domicílio próprio que têm permanecido desconhecidas e ignoradas (Mayock, Parker e Sheridan, 2015; Pleace, 2016b). Em segundo lugar, este estudo emprega uma perspetiva de curso de vida assente na pesquisa biográfica, que é um método de eleição para recolher informação pormenorizada sobre as vidas dos indivíduos no seu todo, para perceber melhor as motivações, as perceções e as experiências individuais e para reconstituir as trajetórias de vida (May, 2000; Atkinson, 2002). Além disso, procedeu-se a observações de teor etnográfico por permitirem captar de modo único a riqueza e a complexidade das experiências quotidianas das pessoas, in loco e no momento em que ocorrem (Brewer, 2000; Hammersley e Atkinson, 2007). Esta abordagem qualitativa pode contribuir para colmatar algumas das lacunas existentes no conhecimento internacional e sobretudo nacional sobre as trajetórias de vida de mulheres em ssA, sobre o modo como chegaram a uma ssA e sobre as suas experiências em ssA ${ }^{6}$.

A recolha de dados decorreu entre dezembro de 2015 e abril de 2018. Foram recrutadas 34 mulheres em ssA ou exclusão habitacional na Área Metropolitana de Lisboa. Os contactos com as participantes foram mediados por serviços de apoio e, noutros casos, foram conduzidos independentemente pela investigadora. Foram elaborados sumários e cronogramas individuais, em que se procurou sintetizar e organizar os dados de cada participante (Patterson, Markey e Somers, 2012), e efetuou-se uma análise de conteúdo temática categorial da informação recolhida (Saldaña, 2009).

Sumariamente, a amostra abrange uma extensa faixa etária que se estende dos 18 aos 68 anos (média de idades de 44.4 anos). A maioria das participantes $(88.2 \%)$ tem nacionalidade portuguesa e frequentou o ensino básico $(69.7 \%)$ 
embora $15.1 \%$ das mulheres tenha completado o ensino superior. $\grave{A}$ data do estudo, a maior parte das participantes (82.4\%) estava desempregada e contava com parcas fontes de rendimento. A maioria destas mulheres $(81.3 \%)$ era solteira ou divorciada e mais de dois terços (76.5\%) eram mães, embora não tivessem os seus filhos menores a cargo.

As duas histórias de vida que se seguem foram selecionadas a partir desta amostra por ilustrarem como várias dimensões das vidas destas mulheres, desde as suas infâncias e adolescências, a par das suas decisões e da conjuntura estrutural em que se inserem, se intersetaram de formas complexas e as conduziram à ssA. As participantes no estudo forneceram o seu consentimento informado. Os nomes que se indicarão de seguida são pseudónimos. Privilegiou-se as vozes das participantes e o seu discurso na primeira pessoa será citado entre aspas.

\section{DUAS HISTÓRIAS DE VIDA NO FEMININO: MARIANA E BENEDITA}

\section{CASO N. ${ }^{\circ}$ 1: MARIANA, 52 ANOS}

Mariana viveu uma "[n]ão infância" empobrecida e foi testemunha de violência na casa da família: "Depois o meu pai [...] bebia muito, batia muito na minha mãe, [...] foi uma coisa que ficou sempre pró resto da vida", "foi um trauma a gente ver a minha mãe ser, ser sempre espancada, levava murros na cabeça e tudo". Mariana nasceu com uma doença ocular que comprometeu seriamente a visão até ter sido operada, o que aconteceu na adolescência. Este problema de saúde teve repercussões na sua vida. Depois de completar a $4 \cdot^{\mathrm{a}}$ classe, a sua professora motivou a família para que ela continuasse os estudos, o que não aconteceu. Ela justificou-o desta forma perante o pai: "eu não vejo o quadro e fazem pouco de mim".

Mariana casou com 17 anos, teve duas filhas e passou a dedicar-se sobretudo à vida familiar. Entretanto o seu relacionamento com o marido deteriorou-se e teve "que o deixar, porque ele também bebia muito, também me batia muito".

Depois iniciou um relacionamento com o companheiro $B$, com quem teve a terceira filha. Passaram por dificuldades financeiras quando ele recebia o ordenado mínimo e ela não encontrava emprego, o que em parte se devia ao facto de morarem fora dos grandes centros urbanos. Em todo o caso, Mariana trabalhou ao longo da sua vida, "assim alternado", como copeira e a tomar conta de pessoas idosas. Numa das fases mais críticas que atravessaram, Mariana recorreu a um serviço de apoio com o intuito de obter uma habitação social ou auxílio monetário para o pagamento da renda da casa. No entanto, esta experiência foi percecionada como negativa e incutiu nela um sentido de 
descrença face à capacidade interventiva dos serviços e o receio de que lhe retirassem as suas filhas. "E então a partir daí eu disse - Eu não... com assistentes sociais eu não quero mais nada. [...] porque é assim, no meio da conversa eu vi que ela... a intenção dela não era m'ajudar [...]. O objetivo dela era tirarem-me a menina e meterem a minha [outra filha] num colégio". Nessa altura mudaram-se para casa de um irmão dela até ao momento em que "resolvemos [...] a nossa situação".

Mariana cuidou dos pais na velhice, acolhendo-os em sua casa, mas isso constituía uma sobrecarga financeira, de forma que se socorreu de apoios sociais. Entretanto, os irmãos entraram em conflito com ela por causa da gestão do dinheiro proveniente das prestações sociais. "E até hoje nunca mais falei com essa minha irmã e os meus irmãos também se foram afastando, por causa tudo de dinheiro".

Quando Mariana tinha 44 anos, o seu companheiro adoeceu gravemente. Após a intervenção cirúrgica a que foi submetido, o companheiro necessitava de cuidados permanentes de que ela se encarregou a tempo inteiro. "[E]u tive que pedir ao meu patrão pra me darem a carta pó desemprego, que não queria indemnização, só queria a carta pó desemprego, pa não ficar sem ganhar, sem receber alguma coisa enquanto eu tratava dele". O companheiro de Mariana acabou por falecer e "foi um dia trágico também". "A partir daí a minha vida desabou toda até hoje".

Depois da morte do companheiro, Mariana recebia o subsídio de desemprego e a pensão de sobrevivência que tinha sido concedida à filha do casal. Não voltou a encontrar emprego, o que atribui à crise económica que assolou o país. Além disso, "hoje em dia, com a minha idade, com a minha escolaridade, e que não tenho carta de condução, é muito difícil arranjar trabalho”. Acrescem as suas limitações de visão, que constituem um entrave ao trabalho na área das limpezas. Mariana antevia que quando o subsídio de desemprego terminasse não teria possibilidade de manter a sua casa porque passaria a dispor somente da pensão de sobrevivência da filha como fonte de rendimento e, por conseguinte, "pagando a renda da casa, eu não tinha dinheiro para comer, tinha que optar, ou pagar a renda da casa ou passarmos fome”. Próximo do término do subsídio de desemprego "tive que deixar a minha casa e desfazer-me de tudo o que eu tinha”. Mariana tinha 48 anos e este foi o início da sua trajetória em ssa.

CASO N. ${ }^{\circ}$ 2: BENEDITA, 38 ANOS

Benedita cresceu "numa barraca" onde vivia com a sua família. Durante a infância e a adolescência foi testemunha de violência: "[o] meu pai batia muito na minha mãe com o álcool". O seu relacionamento com o pai era difícil: "eu sempre defendi a minha mãe, então o meu pai tipo sempre teve um pouco de 
ódio por mim". Quando Benedita tinha 14 anos a sua mãe faleceu e ela saiu de casa da família por conflitos com o pai e porque ele "nunca mais me ajudou". Mudou-se para um quarto, começou a trabalhar em limpezas para custear a renda e, por conseguinte, abandonou a escola, tendo completado o $7 .^{\circ}$ ano de escolaridade.

Motivada por um forte desejo de viver na sua casa, pois "tinha vergonha" de ter vivido numa barraca, Benedita continuou a trabalhar e amealhou dinheiro suficiente para se mudar, aos 16 anos, passando a viver em união de facto com o companheiro C. Cerca de 4 anos depois tiveram uma filha. O relacionamento com este companheiro degradou-se porque ele "metia-se no álcool e no bingo". "[E]u não era feliz, separei-me”. O companheiro nunca contribuiu para o sustento da filha. Benedita recorreu a apoios sociais e trabalhava para fazer face às despesas quotidianas. "[S]empre fui uma granda mulher, lutei, criei a filha sozinha, trabalhei. Tinha dois, três trabalhos, mas consegui. Tinha casa sozinha e filha. Sempre consegui dar a volta, sempre. Eu pagava duzentos euros de creche, mas... Tá a ver? Mais quatrocentos de renda. Eu conseguia sozinha. Trabalhava muito". Benedita trabalhou em fábricas, na área das limpezas e como cozinheira num restaurante. À laia de balanço sobre este período da sua vida e sobre o seu papel como mãe, ela conta: "Sofri muito pa criar a menina. E quero que ela seja muito feliz. [...]. Que tenha o melhor que eu".

Aos 37 anos, Benedita iniciou um relacionamento com o companheiro D e começou a consumir droga, esporadicamente, com ele. "Ele não me obrigou, mas prontos, ele dizia que [...] não viciava e eu confiei". Continuando a refletir sobre o contexto em que desenvolveu uma dependência de droga, ela afirma: “[n]ão sei como, não sei... foi a carência, foi... foi a tristeza também que eu sinto também de pensar que nunca posso dizer que fui uma pessoa muito feliz, isso também tudo... há coisas do passado também não é muito bom viver". Sobre o passado, Benedita esclarece: "É traumas que ficam, coisas que a gente passa. A gente às vezes pensa que consegue superar sozinho, mas não consegue". Ela explica, enfim, como é que perdeu a sua casa: "[d]eixei de trabalhar porque adormecia, fazia diretas a fumar [droga], tinha dinheiro. Era o meu refúgio. Hã deixei de pagar a renda e tive que entregar a casa pa não prejudicar a senhoria".

Em seguida, Benedita recorreu a um serviço de apoio que mediou o contacto com a instituição onde ficou temporariamente alojada. Depois deu entrada numa comunidade terapêutica. "Foi a minha família que me apoiou em ir pá comunidade. E eu pá pa lhes provar que queria mudar fui”. No entanto, não se adaptou à comunidade nem à metodologia de tratamento ali praticada, acabando por abandoná-la. Pediu então ajuda à família, mas recusaram. A seu 
ver, este foi um episódio marcante: “[a] minha família principalmente... ter apoiado, não me ter deixado ficar na rua... acho que as coisas eram diferentes". Nessa altura, os contactos com a família ficaram restringidos à filha e a uma sobrinha, com quem a filha ficou a residir desde a perda da casa. Benedita tinha então 38 anos.

\section{DISCUSSÃO DOS ESTUDOS DE CASO}

A análise destes casos, guiada por uma perspetiva de curso de vida, evidencia aspetos que em larga medida espelham e reforçam a literatura consultada. No quadro 1 explicita-se de que modo os conceitos e os princípios que sustentam a perspetiva de curso de vida podem aplicar-se à análise dos casos apresentados.

Desde logo, foi importante analisar as trajetórias de vida desde a infância, o que permitiu identificar acontecimentos com consequências a longo prazo que contribuíram para delinear as vidas destas mulheres (Ravenhill, 2008). Por exemplo, o abandono escolar precoce e a baixa escolaridade de ambas condicionou o seu perfil de inserção no mercado laboral, o que por sua vez afetou a sua condição financeira. A análise das trajetórias desde a infância também permitiu compreender melhor de que forma os contextos familiares destas mulheres influíram nos seus cursos de vida (Tyler e Schmitz, 2013). Veja-se, a título exemplificativo, como ambas corporizaram o fenómeno de reprodução intergeracional de pobreza ou como os acontecimentos familiares na casa parental de Benedita motivaram a sua transição habitacional prematura e isso se repercutiu nas suas trajetórias educacional e laboral.

Ficou igualmente patente que diversos tipos de trajetórias se intersetaram e influenciaram mutuamente (Hutchison, 2011) tendo conduzido a uma ssA. As duas histórias revelam que dimensões como a família, educação, emprego, fontes de rendimento, proteção social, saúde e habitação podem cruzar-se e articular-se de formas complexas e diversificadas. Acrescem a estas dimensões as intervenções institucionais que, conforme se mostrou, podem exercer uma influência positiva (Benedita obteve alojamento temporário e apoio para entrar numa comunidade terapêutica por via de um serviço de apoio) ou negativa (o desajuste entre as necessidades de Mariana e o que lhe iria ser proposto levou-a a desacreditar este tipo de apoios e a que não voltasse a recorrer a eles até perder a sua casa).

As questões de género são particularmente evidentes no modo como algumas dimensões das vidas destas mulheres - especialmente familiar e laboral evoluíram e se entrecruzaram, culminando numa desvantagem estrutural que agravou o seu risco de chegar a uma ssA. Primeiro, as suas famílias de origem 
QUADRO 1

Aplicação da perspetiva de curso de vida aos estudos de caso

\begin{tabular}{|c|c|c|}
\hline $\begin{array}{c}\text { Conceitos e princí- } \\
\text { pios teóricos }\end{array}$ & Caso n. ${ }^{\circ} 1$ - Mariana & Caso n. ${ }^{\circ} 2$ - Benedita \\
\hline $\begin{array}{l}\text { Infância/ } \\
\text { Adolescência }\end{array}$ & $\begin{array}{l}\text { - Testemunha de violência } \\
\text { doméstica (familiar/estrutural) } \\
\rightarrow \text { Trauma } \\
\text { - Problema de visão (saúde) } \\
\rightarrow \text { Abandono escolar precoce } \\
\text { (educacional) }\end{array}$ & $\begin{array}{l}\text { - Testemunha de violência doméstica } \\
\text { (familiar/estrutural) } \rightarrow \text { Trauma } \\
\text { - Falecimento da mãe e conflito/falta } \\
\text { de apoio do pai (familiar) } \rightarrow \text { Saída } \\
\text { prematura da casa parental (habita- } \\
\text { cional) } \rightarrow \text { Abandono escolar precoce } \\
\text { (educacional); início de atividade } \\
\text { laboral (laboral) }\end{array}$ \\
\hline 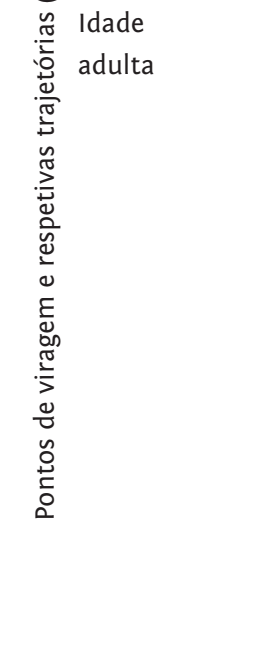 & $\begin{array}{l}\text { - Vítima de violência doméstica } \\
\text { (relacional/estrutural) } \rightarrow \text { Separação } \\
\text { - Experiência negativa em serviço } \\
\text { de apoio } \rightarrow \text { Compromisso da rede } \\
\text { de suporte formal (institucional) } \\
\text { - Conflito com irmãos } \rightarrow \text { Enfra- } \\
\text { quecimento da rede de suporte } \\
\text { informal (familiar) } \\
\text { - Doença/falecimento de compa- } \\
\text { nheiro (relacional) } \rightarrow \text { Desemprego } \\
\text { (laboral); baixas prestações sociais } \\
\text { (estrutural); dificuldades financeiras } \\
\text { (financeira); perda da casa } \\
\text { (habitacional); monoparentalidade }\end{array}$ & $\begin{array}{l}\text { - Separação de companheiro (relacio- } \\
\text { nal) } \rightarrow \text { Monoparentalidade } \\
\text { - Relacionamento com companheiro } \\
\text { (relacional) } \rightarrow \text { Consumo de droga } \\
\text { (saúde); desemprego (laboral); dificul- } \\
\text { dades financeiras (financeira); perda } \\
\text { da casa (habitacional) } \\
\text { - Experiência positiva em serviço de } \\
\text { apoio } \rightarrow \text { Alojamento temporário após } \\
\text { perda da casa (institucional) } \\
\text { - Experiência negativa em comuni- } \\
\text { dade terapêutica } \rightarrow \text { Abandono (insti- } \\
\text { tucional) } \\
\text { - Falta de apoio da família (familiar) } \\
\rightarrow \text { Ausência de alternativas residen- } \\
\text { ciais (habitacional) }\end{array}$ \\
\hline $\begin{array}{l}\text { Temporalidade e } \\
\text { posicionamento } \\
\text { geográfico/social }\end{array}$ & $\begin{array}{l}\text { - Baixo estatuto socioeconómico } \\
\text { - Baixa escolaridade } \\
\text { - Desvantagem no mercado laboral* }\end{array}$ & $\begin{array}{l}\text { - Baixo estatuto socioeconómico } \\
\text { - Baixa escolaridade } \\
\text { - Desvantagem no mercado laboral }\end{array}$ \\
\hline $\begin{array}{l}\text { Vidas } \\
\text { interligadas }\end{array}$ & $\begin{array}{l}\text { - Família de origem } \\
\text { - Colegas de escola } \\
\text { - Relacionamentos íntimos } \\
\text { - Filha } \\
\text { - Profissionais de instituições }\end{array}$ & $\begin{array}{l}\text { - Família de origem } \\
\text { - Relacionamentos íntimos } \\
\text { - Filha } \\
\text { - Profissionais de instituições }\end{array}$ \\
\hline $\begin{array}{l}\text { Ação } \\
\text { humana }\end{array}$ & $\begin{array}{l}\text { - Pedidos de apoio formal e informal } \\
\text { - Decisão de cuidar a tempo inteiro } \\
\text { do companheiro }\end{array}$ & $\begin{array}{l}\text { - Pedidos de apoio formal e informal } \\
\text { - Consumo de droga (em parte como } \\
\text { resposta a trauma/carência afetiva) }\end{array}$ \\
\hline
\end{tabular}

* Associada a idade mais avançada, escassas competências (baixa escolaridade, falta de carta de condução), localização geográfica desvantajosa e crise económica. 
são marcadas por violência de género, que é reproduzida num dos relacionamentos de Mariana e percecionada como um trauma por ambas, tendo repercussões especialmente negativas na vida de Benedita. Em segundo lugar, nas duas histórias é evidente o predomínio de trabalhos pouco qualificados em serviços pessoais e domésticos e na restauração, ocupações tradicionalmente femininas e habitualmente caracterizadas por parca remuneração e forte precariedade. Além disso, uma estreita relação entre a família e a vida profissional, assente em papéis tradicionais de género e resultando numa baixa participação no mercado de trabalho, é notória no caso de Mariana, nomeadamente quando ficou a cuidar das filhas e do companheiro doente. Estes dois aspetos contribuem para um modelo desfavorável de inserção no mercado laboral que expõe as mulheres à pobreza (Perista, Gomes e Silva, 1992) e à ssA. Finalmente, estas histórias contemplam a monoparentalidade, que é reconhecida como um fator de risco para a ssa no feminino, designadamente pela vulnerabilidade socioeconómica de que pode revestir-se (Edgar e Doherty, 2001). Tanto Mariana como Benedita foram responsáveis por famílias monoparentais e aludiram às dificuldades económicas que enfrentaram para fazer face às despesas quotidianas e à manutenção das suas casas.

Estes casos demonstram também os efeitos cumulativos de reveses agudos e crónicos e como estes podem contribuir para desencadear ss A no feminino (Ravenhill, 2008; Kennedy et al., 2010). Olhando para a vida de Mariana no seu todo, percebe-se como ela foi sendo marcada por um baixo estatuto socioeconómico de origem e pautada por uma débil inserção no mercado laboral, fracos recursos financeiros e instabilidade habitacional. A este contexto de base somaram-se: conflitos com os irmãos e consequente enfraquecimento dessa rede de suporte; a doença do companheiro e a decisão e necessidade de se desempregar para cuidar dele a tempo inteiro; e, após o seu falecimento, a inviabilidade de se reempregar (por razões individuais e estruturais), a insuficiência dos apoios sociais e a erosão do rendimento disponível, culminando na impossibilidade de manter a sua casa. Sublinha-se assim, por outro lado, a interdependência das vidas humanas a vários níveis e os modos como as interações sociais interferiram no desenrolar dos cursos de vida destas mulheres (Elder, Johnson e Crosnoe, 2003; Hutchison, 2011). Retomando o exemplo anterior, a doença e o falecimento do companheiro de Mariana, a par do seu papel como cuidadora a tempo inteiro, constituíram um ponto de viragem determinante na sua vida e concretamente na perda da sua casa.

As histórias de Mariana e Benedita revelam que os caminhos que as conduziram a uma ssA são diversificados e que esses processos se desenrolaram nas suas vidas envolvendo, direta e indiretamente, fatores individuais e 
estruturais (Ravenhill, 2008). Por fim, a diversidade destes percursos de vida traz implícita uma lógica não determinista em grande medida assente no papel ativo destas mulheres no delinear das suas trajetórias (Elder, Johnson e Crosnoe, 2003; Hutchison, 2011). É disso exemplo a motivação e a capacidade de trabalho de Benedita, que lhe permitiram, até um certo momento da sua vida, criar uma filha, manter uma casa e assegurar as despesas quotidianas sozinha, revertendo assim uma trajetória de vida marcada por adversidade desde a infância e adolescência.

\section{IMPLICAÇÕES PRÁTICAS E LIMITAÇÕES DA PERSPETIVA DE CURSO DE VIDA}

A perspetiva de curso de vida pode ser um instrumento útil para orientar políticas públicas (McDaniel e Bernard, 2011) e para desenhar e avaliar ações levadas a cabo por serviços de apoio tornando-as mais eficientes (Kennedy et al., 2010). Começa por ser preciso reconhecer que quaisquer medidas deverão ser tanto mais apropriadas e eficazes quanto melhor se conhecer o objeto de intervenção (Ravenhill, 2008). Visto que contribui para compreender melhor os mecanismos subjacentes à ssA, esta perspetiva teórica pode ser usada para guiar intervenções dirigidas às raízes dos problemas e que não sejam meramente paliativas ou perpetuadoras de círculos viciosos (Ravenhill, 2008; McDaniel e Bernard, 2011).

Ao reforçar a importância dos efeitos cumulativos de múltiplas adversidades em esferas distintas, a perspetiva de curso de vida pode ajudar a repensar a SSA como sendo um fenómeno que engloba, mas transcende, a questão habitacional. Esta ideia pode concorrer para implementar e/ou robustecer intervenções mais consentâneas com a multidimensionalidade deste fenómeno e mais ajustadas às necessidades das pessoas em ssA em geral (McDonald, 2011) e das mulheres em particular. Tal como foi assinalado nos casos apresentados, a ssa no feminino surge como um processo que se desenrola ao longo do tempo e que envolve dimensões individuais (ex: relacionais) e estruturais (ex: pobreza, desemprego). Por conseguinte, são necessárias políticas atinentes às circunstâncias adversas individuais e sistémicas que estas pessoas vivenciam no decurso das suas vidas (Ravenhill, 2008; McDaniel e Bernard, 2011). A perspetiva de curso de vida e as histórias de Mariana e Benedita realçam a importância de olhar para a desigualdade social e para o modo como ela pode reproduzir-se e amplificar-se ao longo da vida como focos de intervenção (McDaniel e Bernard, 2011). Considerando o diferencial de género em termos socioeconómicos (Edgar e Doherty, 2001; Mayock e Bretherton, 2016) torna-se evidente que políticas incidindo, por exemplo, no combate à pobreza, 
são fundamentais na intervenção e na prevenção em ssA (Ravenhill, 2008; McDonald, 2011) particularmente no caso das mulheres.

A análise destas histórias segundo a perspetiva de curso de vida permitiu identificar fatores adversos recorrentes (que poderiam constituir-se como alvos de medidas preventivas) e evidenciou pontos de contacto com elementos de redes formais e informais (que poderiam contribuir para prevenir ou mitigar a SSA) (Ravenhill, 2008; McDaniel e Bernard, 2011). Por exemplo, o abandono escolar precoce de Mariana e Benedita não foi, segundo reportado, objeto de sinalização ou intervenção por parte de serviços sociais ou das escolas, os contextos pessoais e familiares em que tal sucedeu não foram apreendidos e fica por saber em que medida apoios dirigidos às necessidades identificadas na altura poderiam representar pontos de viragem nas vidas destas mulheres. Do mesmo modo, ambas foram testemunhas de violência doméstica nas casas parentais mas isso permaneceu fora do radar dos serviços e, portanto, as suas necessidades de suporte a esse nível mantiveram-se ignoradas. Já na idade adulta, estas mulheres recorreram a vários serviços, nomeadamente para requerer apoios sociais, mas estes contactos não se materializaram em pontos de viragem nas suas trajetórias. Seria preciso perceber se e como é que a sinalização destas situações é efetuada nos serviços e equacionar a viabilidade e o benefício de se fazer um seguimento efetivo e consistente destas pessoas após contactos ou intervenções iniciais. Além disso, uma maior divulgação de informação sobre apoios e serviços existentes poderia ser útil para estas mulheres (Ravenhill, 2008), nomeadamente em caso de monoparentalidade, desemprego, término do subsídio de desemprego e dificuldades em assegurar o pagamento de rendas de casa.

Conclui-se com as potenciais limitações da perspetiva de curso de vida. Primeiro, o facto de reconhecer e incorporar diversidade a nível analítico é uma vantagem, mas constitui simultaneamente um problema porque isso pode dificultar ou impossibilitar a identificação de padrões nas trajetórias estudadas. Em segundo lugar, pese embora o desiderato de estabelecer ligações entre os domínios individual e estrutural tal nem sempre é alcançado e, por conseguinte, a prossecução de análises abrangentes segundo esta orientação teórica pode representar um desafio (Hutchison, 2011).

\section{CONSIDERAÇÕES FINAIS}

Uma apreciação crítica sobre o estudo da ssA denota a existência de lacunas, nomeadamente no que concerne aos seus mecanismos causais, sendo que o défice de conhecimento é mais acentuado no caso das mulheres em ssA. A perspetiva de curso de vida pode ser útil para aprofundar o conhecimento 
existente sobre este fenómeno. Em concreto, a investigação guiada por esta orientação teórica tem permitido analisar compreensivamente as trajetórias das pessoas em ssa ao longo do tempo, agregando as dimensões individuais e sistémicas das suas vidas, descortinando como é que elas se intersetam de forma a desencadear a ssA e valorizando a ação humana na evolução dos cursos de vida.

Examinando duas histórias de vida de mulheres em ssa, procurou demonstrar-se que a utilização da perspetiva de curso de vida contribui com conhecimento que ajuda a perceber melhor os mecanismos subjacentes à SsA no feminino em Portugal. Em particular, salientou-se a importância de analisar as vidas das mulheres em ssa desde a infância, o que permite identificar fatores e contextos passíveis de influenciar as suas trajetórias rumo à ssA. Evidenciou-se como fatores individuais e sistémicos contribuíram para formar e moldar várias trajetórias e como elas se entrecruzaram encaminhando estas mulheres para a ssa. Destacaram-se questões de género e de que modo elas intensificaram o risco de uma ssA para estas mulheres, nomeadamente nas dimensões familiar e laboral. Aludiu-se também aos efeitos cumulativos de acontecimentos adversos nas vidas destas mulheres e sublinhou-se o seu papel ativo no delinear dos seus cursos de vida.

Por fim, explicou-se como é que o conhecimento adquirido à luz da perspetiva de curso de vida pode auxiliar os decisores políticos e os serviços de apoio a intervir junto das pessoas em ssa ou em situações de risco, em particular das mulheres, de um modo porventura mais abrangente, concertado, inclusivo e adequado às suas vivências e necessidades. 


\section{REFERÊNCIAS BIBLIOGRÁFICAS}

AtKinson, R. (2002), “The life story interview”. In J. F. Gubrium, J. A. Holstein (eds.), Handbook of Interview Research - Context \& Method, Thousand Oaks, Sage Publications, pp. 121-138. BAptista, I. (2010), “Women and homelessness". In E. O’Sullivan et al. (eds.), Homelessness Research in Europe, Bruxelas, FEANTSA, pp. 163-185.

barros, R. (2010), Contributos de Mulheres Sem-Abrigo para a Construção de Respostas Habitacionais/Serviços de Apoio. Tese de mestrado, Lisboa, ISCTE - Instituto Universitário de Lisboa.

Brewer, J. D. (2000), Ethnography, Buckingham, Open University Press.

Busch-Geertsema, V. (2010), "Defining and measuring homelessness". In E. O'Sullivan et al. (eds.), Homelessness Research in Europe, Bruxelas, FEANTSA, pp. 19-39.

Busch-geertsema, V. et al. (2014), Extent and Profile of Homelessness in European Member States: A Statistical Update, Bruxelas, FEANTSA.

CIAPESSONI, F. (2016), "Homelessness in Uruguay: a trajectories approach". European Journal of Homelessness, 10(2), pp. 113-134.

costa, A. B., Baptista, I. (1999), Women, Exclusion and Homelessness: Access to Services and Opportunities (Portugal) - Annual Report for the European Observatory on Homelessness, Bruxelas, FEANTSA.

Edgar, B., Doherty, J. (eds.) (2001), Women and Homelessness in Europe: Pathways, Services and Experiences, Bristol, The Policy Press.

EDGAR, B. (2012), "The ETHOs definition and classification of homelessness and housing exclusion”. European Journal of Homelessness, 6(2), pp. 219-225.

ELDER JR, G. H., JOHnson, M. K., Crosnoe, R. (2003), "The emergence and development of life course theory”. In J. T. Mortimer, M. J. Shanahan (eds.), Handbook of the Life Course, Nova Iorque, Kluwer Academic/Plenum Publishers, pp. 3-19.

FITZPATRICK, S. (2005), "Explaining homelessness: a critical realist perspective". Housing, Theory and Society, 22(1), pp. 1-17.

GIMAE [Grupo para a Implementação, Monitorização e Avaliação da Estratégia Nacional para a Integração das Pessoas em Situação de Sem-Abrigo] (2018), Inquérito aos Conceitos Utilizados e aos Sistemas Locais de Informação - 2018. Disponível em http://www.enipssa. $\mathrm{pt} /$ documents/10180/11876/Relat $\% \mathrm{C}_{3} \% \mathrm{~B}_{3}$ rio+\%E2\%80\%9CInqu\%C3\%A9rito+aos+ conceitos+utilizados+e+aos+sistemas+locais+de+informa $\mathrm{C}_{3} \% \mathrm{~A} 7 \% \mathrm{C}_{3} \% \mathrm{~A}_{3} \mathrm{O}+\% \mathrm{E}_{2} \% 8 \mathrm{o}$ $\% 93+2018 \% \mathrm{E} 2 \% 80 \% 9 \mathrm{D} / \mathrm{f} 905114 \mathrm{f}-6894-4 \mathrm{afd}-\mathrm{a} 61 \mathrm{e}-2 \mathrm{ba8f1a6a8e2}$ [consultado em 13-12$-2018]$.

Gomes, L. (2002), Feminização dos Sem-Abrigo. Tese de mestrado, Lisboa, Faculdade de Ciências Sociais e Humanas da Universidade Nova de Lisboa.

grenier, A., BARKen, R., MCGrath, C. (2016a), "Homelessness and aging: The contradictory ordering of 'house' and 'home'". Journal of Aging Studies, 39, pp. 73-80.

GRENIER, A. et al. (2016b), "A literature review of homelessness and aging: suggestions for a policy and practice-relevant research agenda". Canadian Journal of Aging, 35(1), pp. 28-41. hammersley, M., AtKinson, P. (2007), Ethnography: Principles in Practice, Londres, Routledge. HENDRICKs, J. (2012), “Considering life course concepts". The Journals of Gerontology, Series B: Psychological Sciences and Social Sciences, 67(2), pp. 226-231.

Hutchison, E. D. (2011), "A life course perspective". In Dimensions of Human Behaviour: the Changing Life Course, Thousand Oaks, Sage Publications, pp. 1-38. 
Iss [Instituto da Segurança Social] (2017), Relatório de Avaliação da Estratégia Nacional para a Integração de Pessoas Sem Abrigo 2009-2015: Prevenção, Intervenção e Acompanhamento, Iss, I. P.

KENNEDY, A. C. et al. (2010), "Risk chains over the life course among homeless urban adolescent mothers: altering their trajectories through formal support”. Children and Youth Services Review, 32, pp. 1740-1749.

LACEy, W. et al. (2016), Single Ageing Women and Housing Security: a Pilot Study of Women Living in the Cities of Unley and Salisbury, Australia, Australian Research Network on Law \& Ageing.

LEe, B. A., Tyler, K. A., Wright, J.D. (2010), “The new homelessness revisited”. Annual Review of Sociology, 36, pp. 501-521.

LÖFstrand, C. H., Quilgars, D. (2016), "Cultural images and definitions of homeless women: implications for policy and practice at the European level”. In P. Mayock, J. Bretherton (eds.), Women's Homelessness in Europe, Londres, Palgrave Macmillan, pp. 41-73.

LOPES, J. R. (2017), A Invisibilidade da Mulher em Situação de Sem-Abrigo - A Neutralidade das Políticas e Respostas Sociais sobre a Integração da Perspectiva Transversal de Gênero em Portugal. Tese de mestrado, Coimbra, Universidade de Coimbra.

Machado, A. (2012), Trajectórias de Exclusão Social em Mulheres Sem-Abrigo: Um Estudo de Caso. Tese de mestrado, Porto, Universidade Católica Portuguesa.

martins, A. F. (2017), As Sem Abrigo de Lisboa - Mulheres que Sonham com uma Casa, Lisboa, Chiado Editora.

MAY, J. (2000), "Housing histories and homeless careers: a biographical approach". Housing Studies, 15(4), pp. 613-638.

mayock, P., Parker, S., Sheridan, S. (2015), Women, Homelessness and Service Provision, Dublin, Simon Communities in Ireland.

MAYOCK, P., BRETHERTON, J. (eds.) (2016), Women's Homelessness in Europe, Londres, Palgrave Macmillan.

MCDANIEL, S., BERNARD, P. (2011), "Life course as a policy lens: challenges and opportunities". Canadian Public Policy - Analyse de Politiques, xxxviI, Supplement/Numéro Spécial, pp. 1-13.

MCDonald, L. (2011), "Examining evictions through a life-course lens". Canadian Public Policy - Analyse de Politiques, xxxviI, Supplement/Numéro Spécial, pp. 115-133.

NEALE, J. (1997), "Homelessness and theory reconsidered". Housing studies, 12(1), pp. 47-61.

nooe, R. M., PATterson, D. A. (2010), “The ecology of homelessness”. Journal of Human Behavior in the Social Environment, 20(2), pp. 105-152.

Parlamento europeu (2016), European Parliament Resolution of 14 April 2016 on Meeting the Antipoverty Target in the Light of Increasing Household Costs (2015/2223 (INI)). Disponível em https://eur-lex.europa.eu/legal-content/EN/TXT/PDF/?uri=CELEX:52016IPO136\&r $\mathrm{id}=3$ [consultado em 04-11-2018].

patterson, M.L., MARKey, M. A., somers, J. M. (2012), "Multiple paths to just ends: using narrative interviews and timelines to explore health equity and homelessness". International Journal of Qualitative Methods, 11(2), pp. 132-151.

Perista, H., Gomes, M. E., silva, M. (1992), A Pobreza no Feminino na Cidade de Lisboa, Lisboa, Comissão para a Igualdade e para os Direitos das Mulheres.

PLEACE, N. (2000), "The new consensus, the old consensus and the provision of services for people sleeping rough”. Housing Studies, 15(4), pp. 581-594. 
PLEACE, N. (2016a), "Researching homelessness in Europe: theoretical perspectives". European Journal of Homelessness, 10(3), pp. 19-44.

PLEACE, N. (2016b), "Exclusion by definition: the under-representation of women in European homelessness statistics". In P. Mayock, J. Bretherton (eds.), Women's Homelessness in Europe, Londres, Palgrave Macmillan, pp. 105-126.

ravenhill, M. (2008), The Culture of Homelessness, Hampshire, Ashgate Publishing Limited.

SALDAÑA, J. (2009), The Coding Manual for Qualitative Researchers, Londres, Sage Publications.

snow, D. A., ANDerson, L., Koegel, P. (1994), "Distorting tendencies in research on the homeless". American Behavioral Scientist, 37(4), pp. 461-475.

somerville, P. (2013), "Understanding homelessness". Housing, Theory and Society, 30(4), pp. 384-415.

TYLER, K. A., SCHMitz, R.M. (2013), "Family histories and multiple transitions among homeless young adults: pathways to homelessness". Children and Youth Services Review, 35, pp. $1719-1726$.

Recebido a 19-02-2019. Aceite para publicação a 02-10-2019.

NOBRE, S. (2020), "Perspetiva de curso de vida: a situação de sem-abrigo no feminino em Portugal”. Análise Social, $235, \mathrm{LV}\left(2 .^{\circ}\right)$, pp. 332-354.

Sónia Nobre » soniaritonobre@hotmail.com » Centro Interdisciplinar de Ciências Sociais (CICs.nOvA), Faculdade de Ciências Sociais e Humanas (FCSH/NOva), Universidade Nova de Lisboa » Avenida de Berna, n. ${ }^{\circ}$ 26-C - 1069-061 Lisboa, Portugal » https://orcid.org/oooo-0002-0475-1245. 